\title{
Development and validation of analytical methodology with focus on the qualification of powder mixers
}

\author{
Pedro de Freitas Fiorante, Rodrigo Dias Martins, Mauri Sergio Alves Palma*
}

Department of Biochemical and Pharmaceutical Technology, School of Pharmaceutical Sciences, University of São Paulo, São Paulo, SP, Brazil

\begin{abstract}
This study aims at developing an analytical procedure capable of quantifying the ferric oxide present in the mixture of ferric oxide/lactose monohydrate $(0.4 \% \mathrm{w} / \mathrm{w})$. The analytical procedure was checked for specificity, linearity, precision (system repeatability, procedure repeatability and intermediate precision), accuracy, stability of solutions and robustness of the procedure. The concentration of Fe (III) was determined by spectrophotometry at $480 \mathrm{~nm}$ based on calibration curves. The specificity was verified. The linearity was obtained in the range of 11.2 to $16.8 \mu \mathrm{g}$ of ferric oxide $/ \mathrm{mL}$. The relative standard deviation (RSD) of the system repeatability, procedure repeatability and intermediate precision, were not more than $2 \%$. The RSD of the accuracy values were less than $0.75 \%$. The stability of the samples was checked over a 24 hours assay. In the robustness evaluation, the wavelength and the concentration of hydrochloric acid varied. The maximum absorbance deviation due to wavelength variation was 0.14 percent, and the maximum deviation due to the hydrochloric acid concentration variation was $2.4 \%$, indicating that the concentration of hydrochloric acid is critical to the analysis of ferric oxide. The procedure developed was validated and is suitable to the performance qualification of powder mixers.
\end{abstract}

Uniterms: Powder mixers/analytical validation. Spectrophotometry. Ferric oxide/quantification. Lactose monohydrate/quantitative analysis.

O objetivo deste trabalho foi desenvolver um método analítico capaz de quantificar o óxido férrico presente na mistura óxido férrico/lactose monoidratada $(0,4 \% \mathrm{w} / \mathrm{w})$. Verificou-se a especificidade, linearidade, precisão (repetibilidade do sistema, repetibilidade do método e precisão intermediária), exatidão, estabilidade das soluções e robustez. A concentração de Fe(III) foi determinada por espectrofotometria em $480 \mathrm{~nm}$ com base em curvas de calibração. Verificou-se a especificidade verificada. A linearidade foi obtida na faixa de 11,2 a $16,8 \mu \mathrm{g}$ de óxido férrico/mL. O desvio padrão relativo (DPR) da repetibilidade do sistema, método e precisão intermediária foram inferiores a $2 \%$. Os valores de DPR da exatidão foram inferiores a $0,75 \%$. A estabilidade das amostras foi verificada ao longo de 24 horas de ensaio. Na avaliação da robustez variou-se o comprimento de onda e a concentração de ácido clorídrico. O desvio máximo de absorbância ao se variar o comprimento de onda foi de $0,14 \%$, enquanto que para a concentração de ácido clorídrico o desvio foi de 2,4\% para a concentração de 0,8 M. Assim, a concentração de ácido clorídrico é crítica para a análise de óxido férrico. O método desenvolvido foi validado e é adequado à qualificação do desempenho de misturadores de pós e granulados.

Unitermos: Misturadores de pós/validação analítica. Espectrofotometria. Óxido férrico/quantificação. Lactose monoidratada/análise quantitativa.

*Correspondence: M. S. A. Palma. Departamento de Tecnologia Bioquímico Farmacêutica. Faculdade de Ciências Farmacêuticas. Universidade de São Paulo. Av. Prof. Lineu Prestes, 580 - Bloco 16 - 05508-000 - São Paulo - SP, Brasil. E-mail: msapalma@usp.br 


\section{INTRODUCTION}

Good manufacturing practices (GMP) are the part of quality assurance, which ensures that products are consistently produced and controlled to quality standards appropriate for the intended use and required by the registry. Compliance with the GMP is oriented primarily to decrease the risks inherent in any pharmaceutical production, which cannot be detected by just analyzing the final products. One must identify which work of qualification and validations are necessary to confirm that all critical aspects of operation are under control in compliance with the GMP (ICH, 2000; ANVISA, 2010).

Qualification is the set of actions taken to verify and record that any installation, system and equipment are properly installed and/or function properly and lead to the expected results. The qualification can be divided into three main steps, being the Installation Qualification (IQ), which are operations performed to ensure that the equipment or system were correctly installed; the Operational Qualification (OQ), which are operations that establish that the equipment or system operates as designed, in all operating ranges considered; and finally the Performance Qualification (PQ), which is a documented verification that the equipment or system features reproducible and consistent performance, according to defined parameters and specifications ( ANVISA, 2010).

The powder mixture, in batch and continuous process, is widely used in pharmaceutical industries. The operation control of mixture of powders and granulates is a crucial step for ensuring the achievement of a final product with the desired characteristics. The quality of products, mainly those of solid pharmaceutical form, depends on the mixing degree of its components, which will ensure the homogeneity of the final product.

The solid pharmaceutical forms have a key role due to its stability, ease of handling and acceptance by patients. For the production of these pharmaceutical forms it is essential to use of powder mixers.

This equipment is responsible for the homogenization of the mixture of powders or granules, having direct impact on uniformity of the final batch produced. Thus, it is clear the need of Performance Qualification of equipment, that is, the verification that the equipment offers reproducible and consistent performance, according to defined parameters and specifications ( ANVISA, 2010).

To ensure the proper functioning of powder mixers, an inexpensive, environmental friendly and simple mix is proposed by mixing ferric oxide and lactose as a performance qualification test. By analyzing the efficiency of this mix it is possible to infer about the proper functioning of these equipment.

The performance validation test does not substitute any process validation, which is specific for each formulation, the particle size and particle distribution and many other aspects which are characteristic of each product.

However, the performance validation test will be a valuable tool to indicate that the equipment is working as it should and as it was during the process validation. In this way, thru periodically verifications or for verification after interventions in the equipment, it is possible to attest the equipment still works as it was during the process validation and, therefore, that the mixing produced for each product, for each mixing program, is still the same as previously validated.

In this work it is proposed as a method of Performance Qualification of this equipment, to accomplish a mixture of ferric oxide $\left(\mathrm{Fe}_{2} \mathrm{O}_{3}\right)$ in lactose in concentration of $0.4 \%$ $\mathrm{w} / \mathrm{w}$. After the mixing process, the sampling of several distinct and representative points in the mixer must be conducted and the analysis of each of these points must be carried out to verify the homogenization of that solid mixture.

The use of ferric oxide and lactose in qualification of powder and granule mixers is an interesting alternative considering that: (1) both products are inexpensive; (2) both are excipients used massively in the pharmaceutical industries and, thus, of easy availability; (3) are products that do not generate environmental impact, since both present no ecotoxicity data (SCIENCELAB, a, b).

The spectrophotometry is an interesting analytical technique because it is simple, inexpensive and more accessible to practically all branches of scientific and industrial activity.

The analytical technique employed in this work for the determination of the homogeneity of the mixture was based on the reaction of Fe (III) ions from ferric oxide mixture, with thiocyanate ( $\mathrm{SCN}-$ ) ions, forming the ferric thiocyanate that exhibits intense blood-red coloration (Vogel, 1979). The analysis of the samples by spectrophotometry in the region of the visible spectrum allowed the quantification of the ferric thiocyanate, and the determination of the concentration of Fe (III) ions, thus enabling the evaluation of the homogenization of the mixture.

The analytical procedure was developed and the methodology validated in accordance to the national legislation and international guides. The purpose of method validation is to demonstrate that the procedure is suitable for the intended purpose. The validation 
shall ensure, by means of experimental studies, that the procedure meets the requirements of the analytical applications, ensuring the reliability of the results ( $\mathrm{ICH}$, 1996; ANVISA, 2003).

In order to be considered validated, quantitative testing methodologies for the determination of the active ingredient in pharmaceutical products or raw materials should be evaluated through the parameters of specificity, linearity, range, precision, accuracy and robustness (ANVISA, 2003).

This work aims at developing and validating a spectrophotometric procedure for quantification of Fe (III) ions in a mixture of ferric oxide and lactose monohydrate making it possible to determine the actual concentration of ferric oxide in the mixture. The analytical procedure will be used later to determine the efficiency of homogenization and on the Performance Qualification of powders and granulates mixers, through a simple, inexpensive and fast strategy.

\section{MATERIAL AND METHODS}

\section{Equipment and reagents}

The following chemicals were used in this study: ammonium ferric sulphate 12-hydrate (J. T. Baker, 99\%), 37\% hydrochloric acid (Merck), purified water (type I), potassium thiocyanate (Sigma-Aldrich, 99\%), Supertab spray-dried lactose monohydrate (DFE pharma) and ferric oxide (Sigma-Aldrich, 99\%). The following apparatus were used in this study: Agilent 8453 UV-Vis spectrophotometer, Varian Cary 50 Bio UV-visible spectrophotometer, Genius ME215S Sartorius analytical balance, heating plate and timer. The following acquisition and processing systems were used for the spectrophotometric data: Cary Win $\mathrm{UV}^{\odot}$ software and HP UV-Vis Win System ${ }^{\odot}$ software. Statistical analysis of the results of validation was performed using the programs Excel $^{\odot}$ and Minitab ${ }^{\odot}$ version 15 and 16.

\section{Samples}

For the development and validation of the procedure, it was used as sample a mixture prepared in the laboratory of ferric oxide in Supertab spray-dried lactose monohydrate in $0.4 \% \mathrm{w} / \mathrm{w}$ concentration.

\section{Preparation of solutions}

\section{Standard Solution}

In order to obtain $11.2 \mu \mathrm{g} / \mathrm{mL}$ concentration of $\mathrm{Fe}$
(III), we weighed $241.8 \mathrm{mg}$ of ammonium ferric sulphate 12-hydrate and transferred to a volumetric flask of $250 \mathrm{~mL}$. It was solubilized with $0.6 \mathrm{~mol}^{-\mathrm{L}^{-1}}$ hydrochloric acid solution up to the flask volume. An aliquot of $5.0 \mathrm{~mL}$ was transferred to a $50 \mathrm{~mL}$ volumetric flask and completed with 0.6 mol. $\mathrm{L}^{-1}$ of hydrochloric acid solution.

\section{Sample Solution}

$1.0 \mathrm{~g}$ of ferric oxide monohydrate lactose mixture $0.4 \%$ was transferred to a $100 \mathrm{~mL}$ volumetric flask and then $5.0 \mathrm{~mL}$ of hydrochloric acid $37 \%$ was added and heated under stirring until complete dissolution of the solid mixture (turbid red solution became a yellowish crystalline solution). After that, the heating was stopped and added, under stirring, about $80 \mathrm{~mL}$ of purified water at room temperature. Once the solution reached room temperature, the flask was filled with purified water. It was taken an aliquot of $10.0 \mathrm{~mL}$ of this solution and transferred to a $25 \mathrm{~mL}$ volumetric flask, which was filled with 0.6 mol. $\mathrm{L}^{-1}$ hydrochloric acid solution. The final concentration of $\mathrm{Fe}$ (III) in the sample was $11.2 \mu \mathrm{g} / \mathrm{mL}$. The control solution was a 0.6 mol. $\mathrm{L}^{-1}$ hydrochloric acid solution.

\section{Analytical procedure}

$10.0 \mathrm{~mL}$ of the sample solution, calibration solution or control solution was reacted, separately, with $2.0 \mathrm{~mL}$ of potassium thiocyanate solution $1.0 \mathrm{~mol} . \mathrm{L}^{-1}$. After exactly one minute, the absorbance was verified at $1.0 \mathrm{~cm}$ optical path quartz cuvette at a wavelength of $480 \mathrm{~nm}$.

\section{Procedure validation}

The analytical procedure was validated according to the parameters described in Resolution RE-899, May 29, 2003 (ANVISA, 2003). The parameters evaluated were: specificity, linearity, precision (System Repeatability, Procedure Repeatability and Intermediate Precision), accuracy, range, procedure robustness and stability of solutions.

\section{Specificity}

The specificity was verified by verifying the absorbance of the chemical solutions used in the quantification of ferric thiocyanate at $480 \mathrm{~nm}$ wavelength. It was evaluated the possible interference of the following solutions:

a. $\quad$ Blank solution (hydrochloric acid 0.6 mol. $\mathrm{L}^{-1}$ ): solvent used to prepare samples and the calibration solution.

b. Potassium thiocyanate solution 1.0 mol.L ${ }^{-1}$ : mixed 
in the ratio of $2.0 \mathrm{~mL}$ to $10.0 \mathrm{~mL}$ of solvent solution according to sample preparation.

c. Lactose monohydrate solution: solution prepared by dissolving $1.0 \mathrm{~g}$ of lactose monohydrate in solvent following the same dilution used in the preparation of the sample solution.

d. Ammonium ferric sulphate 12-hydrate: prepared as described above in item Standard Solution (the absorbance will be verified without reacting with potassium thiocyanate solution).

e. Ferric oxide in lactose monohydrate solution $0.4 \%$ : prepared as described above in item Sample Solution (the absorbance will be verified without reacting with potassium thiocyanate solution).

f. Placebo solution: $2.0 \mathrm{~mL}$ of potassium thiocyanate solution $1.0 \mathrm{~mol} . \mathrm{L}^{-1}$ were added to $10 \mathrm{~mL}$ of solution c.

g. Standard solution: $2.0 \mathrm{~mL}$ potassium thiocyanate solution $1.0 \mathrm{~mol} . \mathrm{L}^{-1}$ were added to $10 \mathrm{~mL}$ of solution "d".

h. Sample solution: $2.0 \mathrm{~mL}$ potassium thiocyanate solution $1.0 \mathrm{~mol} . \mathrm{L}^{-1}$ were added to $10 \mathrm{~mL}$ of the solution "e".

Acceptance criteria: the measured absorbance of the solutions “a”, “b”, “c”, “d”, “e” and “f”, at 480 nm, must not be greater than $1.0 \%$ of the absorbance obtained for the sample solution.

\section{Linearity}

The linearity was evaluated in the range of $10 \%$ to $150 \%$ of the target concentration (11.2 $\mu$ g of Fe (III) $/ \mathrm{mL}$ ), in 5 different concentration levels and in triplicate.

Three stock solutions were prepared at a concentration of $112.0 \mu \mathrm{g} / \mathrm{mL}$ of Fe (III) (1000\%) using ferric ammonium sulfate 12-hydrate, and from each of these solutions, dilutions were performed in order to obtain levels 10\%, 25\%, 50\%, 100\% and 150\% (in triplicate).

Ferric ammonium sulfate 12 -hydrate had its concentration determined prior to the test (ACM, 2000).

Acceptance criteria: the calibration curve shall follow a linear model with linear correlation coefficient $\mathrm{r}^{2}$-value $\geq 0.9990$. The lack of adjustment model test (lack of fit test) must be statistically significant ( $p$-value $>0.05$ ).

\section{Range}

The results obtained in linearity, accuracy and precision tests of the procedure were evaluated to determine the method range.

Acceptance criteria: the range of the procedure shall be in accordance with the levels obtained for linearity, accuracy and precision.

\section{Precision}

The precision was tested at three levels: repeatability of the system, repeatability of the procedure and intermediate precision.

Acceptance criteria: the procedure should meet the acceptance criteria established for the three evaluated levels of accuracy.

\section{Repeatability}

- System

It was evaluated through a sequential reading, performed six times, of the same sample solution.

Acceptance criteria: the relative standard deviation among the six readings shall be less than $2.0 \%$.

- Procedure

The repeatability of the procedure was determined by comparing the results of two analyses, carried out by the same analyst, with the same equipment and batch, in each of six replicate sample solutions.

Acceptance criteria: the relative standard deviation among the twelve readings shall be less than $2.5 \%$.

\section{Intermediate Precision}

Intermediate precision was determined by comparing the results of two analyses of the same batch, carried out in two days, by two analysts, and using different equipment, through the analysis of six replicates samples.

Acceptance criteria: the relative standard deviation among the twelve readings shall be less than 3.0\%.

\section{Accuracy}

The accuracy was assessed at levels of 50\%, 100\% and $150 \%$, in triplicate, according to the adopted work concentration $(11.2 \mu \mathrm{g} / \mathrm{mL})$. It was analyzed simulated samples of the mixture, which had the same concentration of ferric oxide found in the sample solution. The simulated samples were prepared through the contamination of solutions containing lactose monohydrate (placebo).

Ferric oxide had its concentration determined prior to the test (Vogel, 1983).

Acceptance criteria: the recovery percentage (R\%) for each level of concentration shall be in the range of $97.0 \% \leq \mathrm{R} \leq 103.0 \%$. The relative standard deviation for each level of concentration shall be less than $2.5 \%$.

\section{Robustness}

The robustness of the procedure was evaluated regarding hydrochloric acid concentration in the solvent solution $\left(0.6 \mathrm{~mol}^{-1} \mathrm{~L}^{-1}\right)$ and the reading wavelength (480 nm) according to Table I.

For the assessment of the concentration of the 
TABLE I - Parameters evaluated in the robustness of the procedure

\begin{tabular}{lllll}
\hline \multirow{2}{*}{ Parameter } & & \multicolumn{3}{c}{ Level } \\
\cline { 3 - 5 } & & $\mathbf{( - )}$ & $\mathbf{( o )}$ & $\mathbf{( + )}$ \\
\hline $\mathrm{A}$ & HCl concentration in the solvent $(\mathrm{M})$ & 0.4 & 0.6 & 0.8 \\
\hline $\mathrm{B}$ & Wavelength $(\mathrm{nm})$ & 475 & 480 & 485 \\
\hline
\end{tabular}

solvent solution, samples were prepared with the challenge concentrations, and the calibration solution with the concentration described in the procedure $\left(0.6 \mathrm{~mol} . \mathrm{L}^{-1}\right)$.

For the assessment of the influence of the wavelength, the absorbance of the samples and the calibration solutions were read in the challenge wavelengths.

Acceptance criteria: the answer obtained for the challenge levels shall not have a deviation greater than $2.0 \%$.

\section{Stability of Solutions}

The stability of the calibration solutions and the sample solutions were evaluated during a $24 \mathrm{~h}$ period at room temperature.

It was prepared two calibration solutions and three sample solutions that were reacted and read in time zero, 2, 4, 6 and $24 \mathrm{~h}$. The answer obtained in each time was compared to the response obtained in time zero of each solution.

Acceptance criteria: the absorbance readings in relation to the time zero shall not have a deviation greater than $3.0 \%$.

\section{RESULTS AND DISCUSSION}

\section{Development of analytical procedure}

The analytical procedure was developed based on the reaction of Fe (III) ions present in the sample solution with $\mathrm{SCN}^{-}$ions forming ferric thiocyanate complex $\left[\mathrm{Fe}(\mathrm{SCN})_{3}\right]$ of intense blood-red coloration. Then, the obtained solution was analyzed by absorption spectrophotometry in the visible band to determine the concentration of the ferric thiocyanate, and consequently, the concentration of Fe (III) ions in the sample solution.

To determine the ideal concentration of Fe (III) ions in the sample solution, solutions were prepared in 7 different concentrations (covering the range of 0.5 to $100 \mu \mathrm{g} / \mathrm{mL}$ ). The solutions were prepared with ammonium ferric sulfate 12 -hydrate in $0.05 \mathrm{~mol}^{-1} \mathrm{~L}^{-1}$ hydrochloric acid solution, and in each $10 \mathrm{~mL}$ sample were added $2 \mathrm{~mL}$ of 1.0 mol. $\mathrm{L}^{-1}$ potassium thiocyanate. It was determined that the work range would be close to $10 \mu \mathrm{g} / \mathrm{mL}$ for which the absorbance was near to 1.0.

The sample solution with concentration of $10 \mu \mathrm{g} / \mathrm{mL}$ was prepared by dissolving a $1.0 \mathrm{~g}$ mixture of ferric oxide in lactose monohydrate $0.4 \%$ (containing $2.8 \mathrm{mg}$ of Fe (III) per $1.0 \mathrm{~g}$ of mixture) in $100 \mathrm{~mL}$ of solvent. The preparation was followed by the dilution of $10 \mathrm{~mL}$ of this solution to $25 \mathrm{~mL}$ with solvent, resulting in a solution with concentration of $11.2 \mu \mathrm{g} / \mathrm{mL}$ of Fe (III).

Due to the low solubility of ferric oxide in aqueous solutions, a new strategy was required for the sample solubilization, since the $0.05 \mathrm{~mol}$ hydrochloric acid. $\mathrm{L}^{-1}$ was not effective in solubilizing the ferric oxide. Tests were carried out with more concentrated hydrochloric acid solutions, however the solubilization of the sample was only possible in 37\% hydrochloric acid under intense heating and constant agitation. Immediately after solubilization, it was added sufficient amount of water in order to achieve the final concentration of 0.6 mol. $\mathrm{L}^{-1}$ of hydrochloric acid

The absorbance was read in $1.0 \mathrm{~cm}$ optical path quartz cuvette. The spectrum of scanning in the UV-Vis region exhibited a maximum absorption at $480 \mathrm{~nm}$, as shown in Figure 1, solution "h". This wavelength was adopted as the wavelength for the quantification of ferric ion in the samples.

During the development of the procedure, it was verified that, after the reaction of Fe (III) with the thiocyanate, forming the ferric thiocyanate, a time dependent decrease of the absorbance at $480 \mathrm{~nm}$ occurred. This observation led to the standardization of the reading time after adding 1.0 mol. $\mathrm{L}^{-1}$ ferric thiocyanate solution in exactly one minute.

The concentration of the sample solution was determined in relation to the calibration solution, a solution of known concentration of ferric ammonium sulfate, previously standardized. The concentration of the sample solution was calculated according to the beer-Lambert law.

\section{Specificity}

The results to verify the specificity of the procedure are presented in Figure 1 and Table II. The analytical procedure was shown to be specific for the quantification 
of ferric thiocyanate. The analysis of spectra obtained for scanning solutions "a" through "f" showed no interference at $480 \mathrm{~nm}$ wavelength for these solutions. Absorbance values obtained at $480 \mathrm{~nm}$ for each of these solutions was $1.0 \%$ lower than the ones obtained in the sample solution.

\section{Linearity}

Results of the linearity are presented in Figures 2 and 3.
The linearity of the procedure proved to be adequate in the evaluated range. The calibration curve follows a linear model with $r^{2} \geq 0.9990$. The analysis of the standardized residues indicates that the residues are randomly distributed and normalized. The "lack of fit" test has value $\mathrm{p}>0.05$, indicating that the alternative hypothesis should be rejected. Therefore, we can conclude that the procedure does not present "lack of fit", or in other words, the model fits properly.
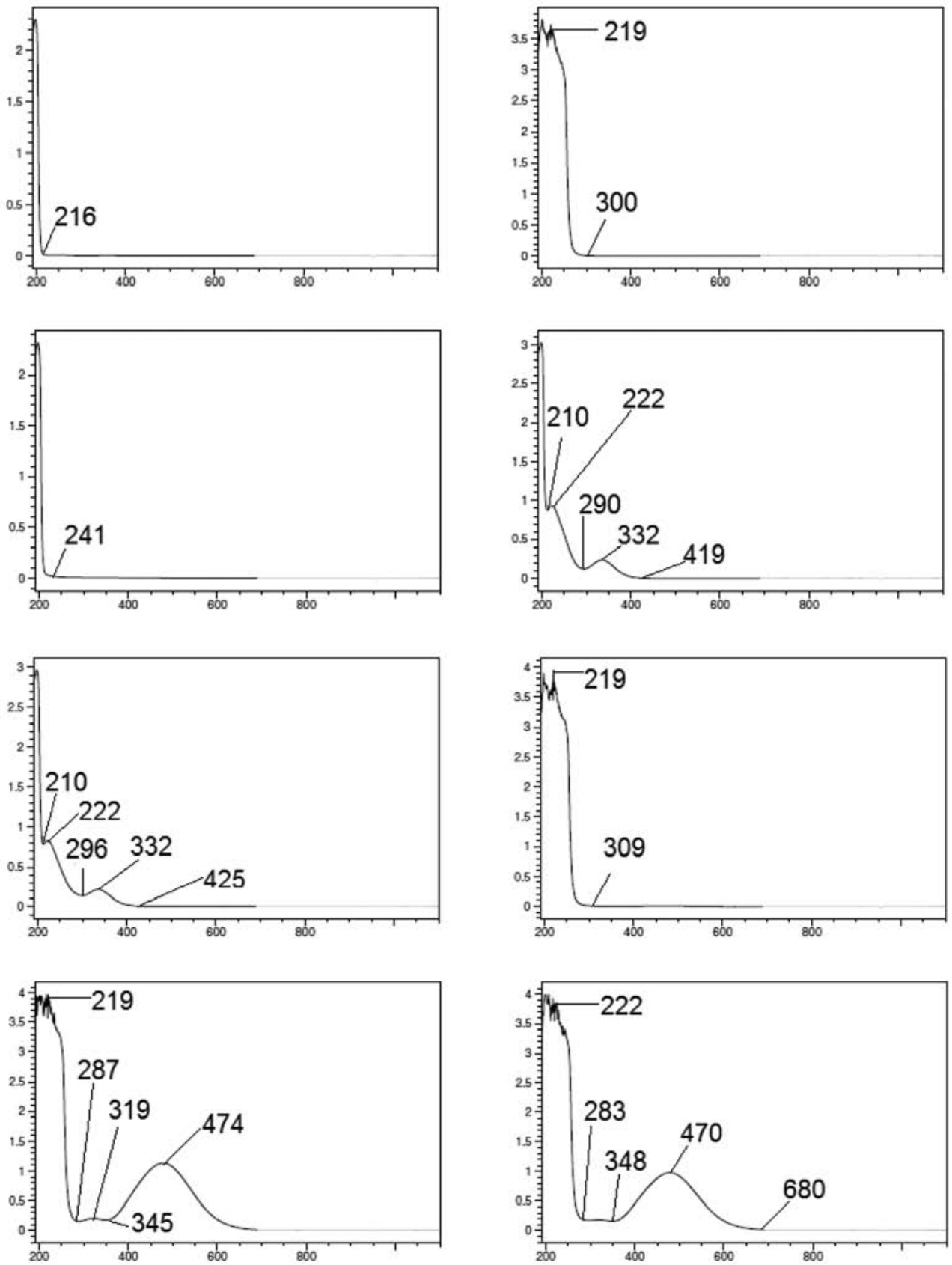

FIGURE 1 - Spectrum scan of the solutions "a”, "b”, “c”, “d”, "e”, "f”, "g” and "h”. 
TABLE II - Absorbance of the solutions at $480 \mathrm{~nm}$ relative to the sample solution for verification of the specificity of the procedure

\begin{tabular}{lcc}
\hline Solution & Absorbance & Relative absorbance (\%) \\
\hline a - Solvent & 0.001204 & 0.123 \\
b - Potassium thiocyanate & 0.002003 & 0.204 \\
c - Lactose monohydrate & 0.000926 & 0.094 \\
d - Ammonium ferric sulphate & 0.000009 & 0.001 \\
e - Ferric oxide in lactose & 0.007113 & 0.725 \\
f - Placebo & 0.008641 & 0,881 \\
g - Calibration solution & 1.1362 & - \\
h- Sample solution & 0.98066 & 100.000 \\
\hline
\end{tabular}

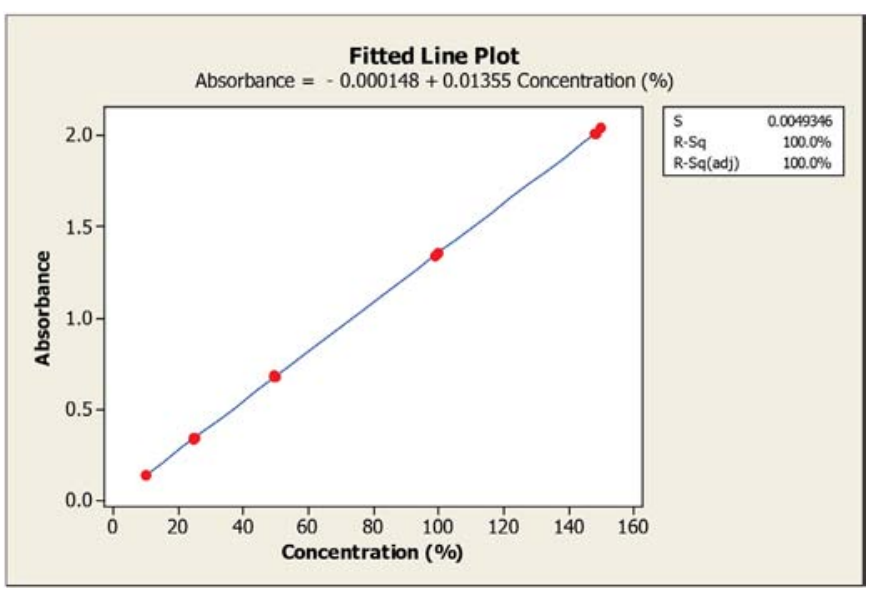

FIGURE 2 - The linearity of the procedure for concentrations from $10 \%$ to $150 \%$ (in relation to a $11.2 \mu \mathrm{g} / \mathrm{mL}$ concentration).

\section{Range}

The range of the procedure was evaluated based on linearity and accuracy, as shown in Table III, and verified by the tests of accuracy.

\section{Precision}

\section{Repeatability of the System}

The results of the repeatability of the system are presented in Table IV.

\section{Repeatability of the Procedure}

The results of the Repeatability of the Procedure are presented in Table $\mathrm{V}$.

The hypothesis analysis to assess the equality of average values shown in Table V (two-sample $t$ ) showed a p-value exceeding 0.05 , indicating that both tests showed the results were statistically equivalent.

\section{Intermediate Precision}

Results of the intermediate precision are presented in Table VI.

The hypothesis analysis to assess the equality of average values shown in Table V (two-sample $t$ ) showed a p-value exceeding 0.05 , indicating that both tests showed the results were statistically equivalent.

The procedure presented satisfactory precision of the repeatability of the system, repeatability of the procedure and intermediate precision. The analysis of the results shown in Tables IV, V and VI reveals a small dispersion in them, showing that the procedure is able to generate reproducible results. The hypothesis tests performed on tests of repeatability of the procedure and intermediate precision stated that the average values obtained from the analysis 01 and 02 are statistically equivalent.

\section{Accuracy}

The results of accuracy are shown in Table VII.

The individual results obtained on recovery tests for concentration levels from $50 \%$ to $150 \%$ showed suitable recovery percentage and RSD. The accuracy of the procedure is confirmed in the concentration range from $50 \%$ to $150 \%$.

\section{Robustness}

The results of the robustness of the procedure are presented in the Tables VIII and IX.

The results presented in Table VIII shows that the change in wavelength in $\pm 5 \mathrm{~nm}$ did not cause relevant impact on the results. Therefore, the procedure is robust to minor variations in the wavelength. The results presented in Table IX show that the change in the concentration 

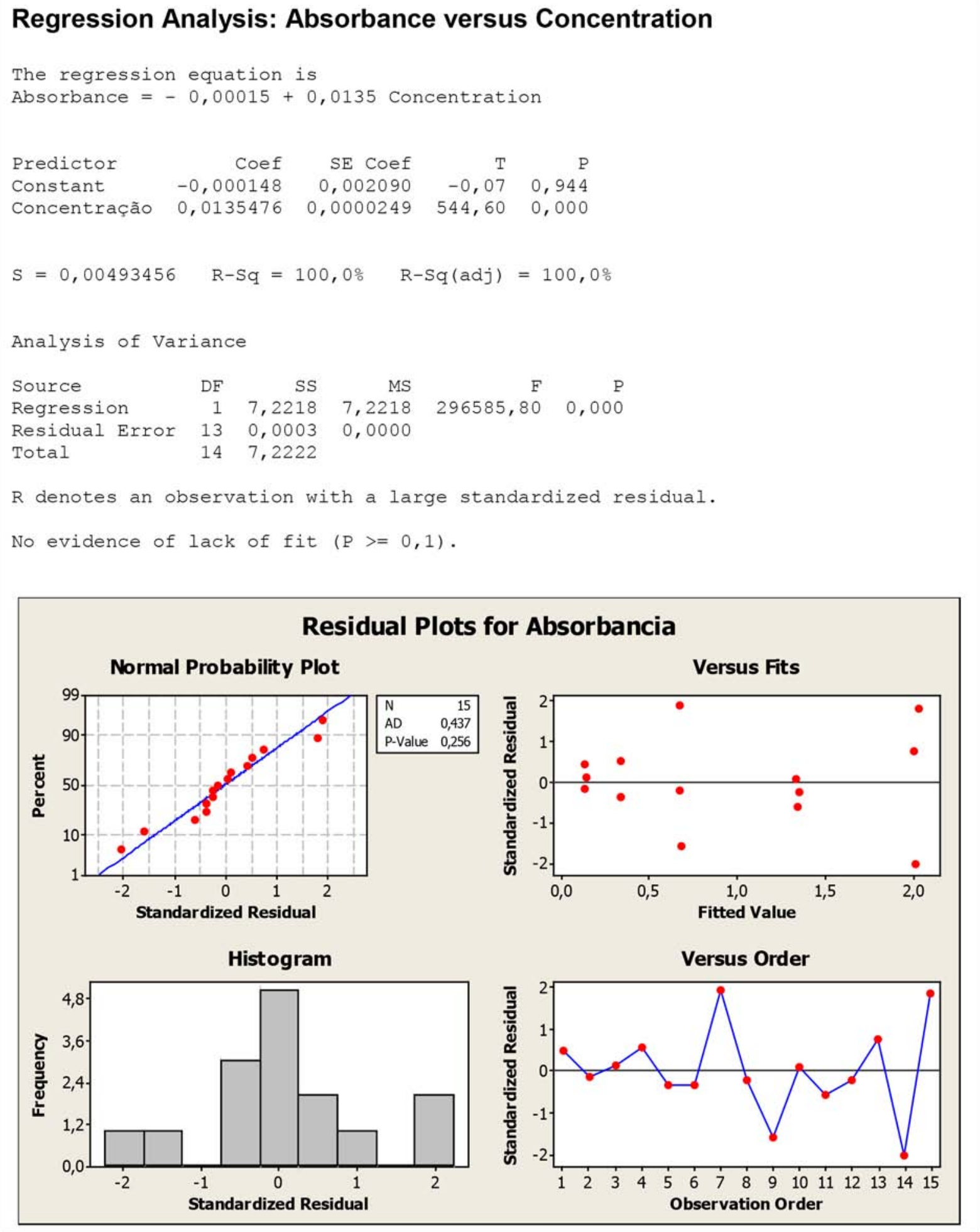

FIGURE 3 - Regression analysis of the results of linearity.

of hydrochloric acid in the solvent solution showed no significant impact when this concentration was reduced to 0.4 mol.L-1. However, when the concentration was elevated to $0.8 \mathrm{~mol} . \mathrm{L}^{-1}$ the variation became significant (deviation greater than 2\%). Therefore, the adoption of solvent concentration is a potentially critical point to the analysis of ferric oxide when the concentration of hydrochloric acid is increased. 
TABLE III - Range determined according to the linearity and accuracy (nominal concentration of Fe (III) = $11.2 \mu \mathrm{g} / \mathrm{mL}$ )

\begin{tabular}{lcccc}
\hline \multirow{2}{*}{ Parameter } & \multicolumn{4}{c}{ Range } \\
\cline { 2 - 5 } & \multicolumn{2}{c}{ Fe (III) concentration in solution $(\boldsymbol{\mu g} / \mathbf{m L})$} & \multicolumn{2}{c}{ Relative concentration of Fe (III) (\%) } \\
\cline { 2 - 5 } & Minimum & Maximum & Minimum & Maximum \\
\hline Linearity & 1.11 & 16.81 & 9.89 & 150.11 \\
Accuracy & 5.72 & 17.17 & 51.06 & 153.29 \\
Range & 5.72 & 16.81 & 51.06 & 150.11 \\
\hline
\end{tabular}

TABLE IV - Results of the repeatability of the system

\begin{tabular}{|c|c|c|c|c|}
\hline Sample & $\begin{array}{c}\text { Abs } \\
480 \mathrm{~nm}\end{array}$ & Average & SD & $\begin{array}{l}\text { RSD } \\
(\%)\end{array}$ \\
\hline 1 & 1.3010 & \multirow{6}{*}{1.2973} & \multirow{6}{*}{0.003} & \multirow{6}{*}{0.21} \\
\hline 2 & 1.3001 & & & \\
\hline 3 & 1.2969 & & & \\
\hline 4 & 1.2952 & & & \\
\hline 5 & 1.2968 & & & \\
\hline \multirow[t]{2}{*}{6} & 1.2939 & & & \\
\hline & & & ptance & $\leq 2,0 \%$ \\
\hline
\end{tabular}

TABLE V - Results of the repeatability of the procedure

\begin{tabular}{|c|c|c|c|}
\hline Analysis & $\begin{array}{c}\mathrm{Fe}(\mathrm{III}) \text { concentration in } \\
\text { lactose monohydrate (mg/g) }\end{array}$ & Average & RSD (\%) \\
\hline \multirow{6}{*}{1} & 2.80309 & \multirow{6}{*}{2.7702} & \multirow{6}{*}{$0.97 \%$} \\
\hline & 2.76758 & & \\
\hline & 2.77463 & & \\
\hline & 2.75885 & & \\
\hline & 2.72600 & & \\
\hline & 2.79097 & & \\
\hline \multirow{6}{*}{2} & 2.79332 & \multirow{6}{*}{2.7638} & \multirow{6}{*}{$1.00 \%$} \\
\hline & 2.75682 & & \\
\hline & 2.77784 & & \\
\hline & 2.77096 & & \\
\hline & 2.77085 & & \\
\hline & 2.71285 & & \\
\hline Avreage & 2.76698 & & \\
\hline RSD & $0.95 \%$ & & \\
\hline Acceptance criterion & $\leq 2.5 \%$ & & \\
\hline
\end{tabular}

\section{Stability}

The results of the stability of the solutions are presented in Tables X and XI.

The calibration and sample solutions are satisfactorily stable for a 24 -hour period. The results show that at the time range studied, neither the calibration nor the sample solution presented any significant deviation to the absorbance time zero. 
TABLE VI - Results of the intermediate precision

\begin{tabular}{|c|c|c|c|c|c|}
\hline Analysis & Day & Spectrophotometer & $\begin{array}{c}\text { Fe (III) } \\
\text { concentration } \\
\text { in lactose } \\
\text { monohydrate } \\
(\mathrm{mg} / \mathrm{g}) \\
\end{array}$ & Average & RSD (\%) \\
\hline \multirow{6}{*}{1} & \multirow{6}{*}{1} & \multirow{6}{*}{1} & 2.70702 & \multirow{6}{*}{2.6558} & \multirow{6}{*}{$1.62 \%$} \\
\hline & & & 2.58744 & & \\
\hline & & & 2.67526 & & \\
\hline & & & 2.65984 & & \\
\hline & & & 2.68019 & & \\
\hline & & & 2.62528 & & \\
\hline \multirow{9}{*}{2} & \multirow{9}{*}{2} & \multirow{6}{*}{2} & 2.65506 & \multirow{6}{*}{2.6689} & \multirow{6}{*}{1.98} \\
\hline & & & 2.70878 & & \\
\hline & & & 2.59777 & & \\
\hline & & & 2.66432 & & \\
\hline & & & 2.74758 & & \\
\hline & & & 2.63992 & & \\
\hline & & Average & 2.66237 & & \\
\hline & & RSD & $1.74 \%$ & & \\
\hline & & Acceptance criterion & $\leq 3.0 \%$ & & \\
\hline
\end{tabular}

TABLE VII - Results of accuracy

\begin{tabular}{lccc}
\hline \multirow{2}{*}{ Relative concentration (\%) } & Recuperation (\%) & Average (\%) & RSD (\%) \\
\cline { 2 - 3 } 50 & 101.38 & 101.63 & 0.57 \\
\hline & 102.29 & & 0.33 \\
& 101.21 & 101.50 & \\
100 & 101.13 & & 0.53 \\
& 101.59 & 101.65 & \\
150 & 101.77 & & \\
\hline R (\%) & 101.58 & & \\
RSD (\%) & 101.14 & & \\
\hline Acceptance criterion (R) & 102.22 & & \\
\hline Acceptance criterion (RSD) & 101.59 & & \\
\hline
\end{tabular}

\section{CONCLUSIONS}

A new procedure to determine the concentration of Fe (III) ions in a mixture of ferric oxide and lactose monohydrate was developed. It is simple, fast and uses as analytical technique the spectrophotometry in the visible region and common reagents used in physical-chemical laboratories.

The analytical methodology has been validated in accordance with Brazilian laws. The procedure has 
TABLE VIII - Results of the robustness of the procedure in relation to the wavelength. ( $\mathrm{HCl} 0.6 \mathrm{~mol} / \mathrm{L}$ )

\begin{tabular}{llll}
\hline \multirow{2}{*}{ Sample } & \multicolumn{3}{l}{ Fe (III) concentration in lactose monhydrate $\mathbf{( m g} / \mathbf{g})$} \\
\cline { 2 - 4 } & Wavelenght $\mathbf{( n m )}$ & $\mathbf{4 8 5}$ \\
\hline $\mathbf{4 7 5}$ & 2.68959 & $\mathbf{4 8 0}$ & 2.68887 \\
2 & 2.6535 & 2.68857 & 2.64973 \\
3 & 2.64727 & 2.65518 & 2.64670 \\
\hline Average & 2.66350 & 2.65272 & 2.66180 \\
RSD & 0.86 & 2.66550 & 0.88 \\
WRD (\%) & 99.92 & 0.75 & 99.86 \\
\hline Acceptance
\end{tabular}

Acceptance criterion $\quad \mathbf{9 8 . 0} \leq \mathrm{WRD} \leq \mathbf{1 0 2 . 0}$

Note: $\mathrm{WRD}=$ wavelength relative deviation, calculated as the relation between the given average concentration values and the average concentration value for $\lambda=480 \mathrm{~nm}$.

TABLE IX - Results of the robustness of the procedure in relation to the hydrochloric acid in the solvent solution $(\lambda=480 \mathrm{~nm})$

\begin{tabular}{lccc}
\hline \multirow{3}{*}{ Sample } & \multicolumn{3}{c}{ Fe (III) em Lactose (mg/g) } \\
\cline { 2 - 4 } & \multicolumn{3}{c}{ HCl (mol.L $\left.\mathbf{~}^{-\mathbf{1}}\right)$} \\
\cline { 2 - 4 } & $\mathbf{0 . 4}$ & $\mathbf{0 . 6}$ & $\mathbf{0 . 8}$ \\
\hline 1 & 2.71685 & 2.68857 & 2.59516 \\
3 & 2.69622 & 2.65518 & 2.65234 \\
\hline Average & 2.62164 & 2.65272 & 2.55677 \\
RSD (\%) & 2.67820 & 2.66550 & 2.60140 \\
HRD (\%) & 1.87 & 0.75 & 1.85 \\
\hline Accp & 100.48 & 100.00 & 97.60 \\
\hline
\end{tabular}

\section{Acceptance criterion}

98.0 $\leq$ HRD $\leq 102.0$

Note: $\mathrm{HRD}=$ hydrochloric acid relative deviation, calculated as the relation between the given average concentration values and the average concentration value for $\mathrm{HCl}$ concentration $=0.6 \mathrm{Mol} \cdot \mathrm{L}^{-1}$.

TABLE X - Results of the stability of the calibration solutions $(\lambda=480 \mathrm{~nm})$

\begin{tabular}{ccccccc}
\hline \multicolumn{2}{l}{ Calibration solution } & t-zero & $\mathbf{t}-\mathbf{2} \mathbf{~ h}$ & $\mathbf{t}-\mathbf{4} \mathbf{h}$ & $\mathbf{t}-\mathbf{6} \mathbf{h}$ & $\mathbf{t}-\mathbf{2 4} \mathbf{~ h}$ \\
\hline \multirow{2}{*}{1} & Absorbance & 1.32130 & 1.31990 & 1.32220 & 1.31710 & 1.32450 \\
& TRD (\%) & 100.00 & 99.89 & 100.07 & 99.68 & 100.24 \\
\hline \multirow{2}{*}{2} & Absorbance & 1.32110 & 1.31990 & 1.32410 & 1.32090 & 1.32700 \\
& TRD (\%) & 100.00 & 99.91 & 100.23 & 99.98 & 100.45 \\
\hline \multicolumn{7}{l}{ Acceptance criterion (\%) } \\
\hline
\end{tabular}

Note: TRD = Time zero relative deviation, calculated as the relation between the given absorbance values and the absorbance value for t-zero.

specificity, linearity, accuracy, precision (repeatability of the system, repeatability of the procedure and intermediate precision) and adequate range. The robustness of the procedure to small wavelength variations was verified. However, the concentration of hydrochloric acid in the solvent solution is critical for the analytical procedure and therefore should be controlled. Calibration and sample solutions presented stability for a 24-hour test when stored at room temperature.

The developed procedure was validated and is 
TABLE XI - Results of the stability of the sample solutions $(\lambda=480 \mathrm{~nm})$

\begin{tabular}{ccccccc}
\hline \multicolumn{2}{l}{ Sample Solution } & t-zero & $\mathbf{t}-\mathbf{2} \mathbf{h}$ & $\mathbf{t}-\mathbf{4} \mathbf{h}$ & $\mathbf{t}-\mathbf{6} \mathbf{h}$ & $\mathbf{t}-\mathbf{2 4} \mathbf{h}$ \\
\hline \multirow{2}{*}{1} & Absorbance & 1.38930 & 1.38100 & 1.38700 & 1.38330 & 1.39170 \\
& TRD (\%) & 100.00 & 99.40 & 99.83 & 99.57 & 100.17 \\
\hline \multirow{2}{*}{2} & Absorbance & 1.36250 & 1.35390 & 1.36080 & 1.35420 & 1.35590 \\
& TRD (\%) & 100.00 & 99.37 & 99.88 & 99.39 & 99.52 \\
\hline \multirow{2}{*}{3} & Absorbance & 1.33240 & 1.32530 & 1.33090 & 1.32430 & 1.33250 \\
& TRD (\%) & 100.00 & 99.47 & 99.89 & 99.39 & 100.01 \\
\hline \multicolumn{7}{r}{} \\
& Acceptance criterion (\%) & & $\mathbf{9 7 . 0 \%} \leq$ TRD $\leq \mathbf{1 0 3 0 \%}$ & \\
\hline
\end{tabular}

Note: TRD $=$ Time zero relative deviation, calculated as the relation between the given absorbance values and the absorbance value for t-zero.

suitable for the proposed objective, i.e., to assess the concentration of ferric oxide in ferric oxide mixture in lactose monohydrate, as proven by meeting all the proposed acceptance criteria, and to serve as a tool in the qualification of performance of industrial powder and granule mixers.

Therefore, it is demonstrated the effectiveness of an important tool on the performance qualification of powder mixers. Thru the method developed and validated it is possible to test and qualify powder mixers in periodically verifications or for verification after interventions in the equipment assuring the accomplishment of the Good Manufacturing Practices.

\section{ACKNOWLEDGMENTS}

The authors would like to thank the company Daiichi Sankyo Brazil Pharmaceutical for the great opportunity to develop this study and for all the support during the project. The authors would also like to thank the Faculty of Pharmaceutical Sciences of the University of São Paulo.

\section{REFERENCES}

AMERICAN CHEMICAL SOCIETY. (ACM). Reagent chemicals. 9. ed. New York. American Chemical Society, 2000. $768 \mathrm{p}$.

AGÊNCIA NACIONAL DE VIGILÂNCIA SANITÁRIA. ANVISA. Resolução RE n. ${ }^{\circ} 899$ de 29 de maio de 2003. Determina a publicação do "Guia para validação de métodos analíticos e bioanalíticos”. Diário Oficial da União, Brasília, 02 jun. 2003.
AGÊNCIA NACIONAL DE VIGILÂNCIA SANITÁRIA. ANVISA. Resolução RDC n. ${ }^{\circ} 17$, de 16 de abril de 2010. Dispõe sobre as boas práticas de fabricação de medicamentos. Diário Oficial da União, Brasília, 19 abr. 2010.

INTERNATIONAL CONFERENCE ON HARMONIZATION. ICH. Guideline Q2-R1: validation of analytical procedures: text and methodology. [S.l.]: International Conference on Harmonization, 1996.

INTERNATIONAL CONFERENCE ON HARMONIZATION. ICH. Guideline Q7: Good manufacturing practice guide for active pharmaceutical ingredients. [S.l.]: International Conference on Harmonization, 2000.

SCIENCELAB.COM. Material safety data sheet: lactose, anhydrous MSDS. Disponível em: <http://www.sciencelab. com/msds.php?msdsId=9924450 $>$. Acesso em: 14 nov. 2013a.

SCIENCELAB.COM. Material safety data sheet: ferric oxide MSDS. Disponível em: <http://www.sciencelab.com/msds. php?msdsId=9924041 $>$. Acesso em: 14 nov. 2013b.

VOGEL, A. I. Química analítica qualitativa. Tradução Antonio Gimeno. 5. ed. São Paulo: Mestre Jou, 1979. p. 347-350.

Received for publication on $15^{\text {th }}$ January 2014 Accepted for publication on $03^{\text {rd }}$ March 2015 